\title{
Synaptic Physiology of Horizontal Connections in the Cat's Visual Cortex
}

\author{
Judith A. Hirsch and Charles D. Gilbert \\ Laboratory of Neurobiology, The Rockefeller University, New York, New York 10021
}

\begin{abstract}
Horizontal connections are a principal component of intrinsic cortical circuitry. They arise mainiy from pyramidal cells and course parallel to the brain's surface for distances as long as $8 \mathrm{~mm}$, linking columns with shared orientation preference and allowing cells to integrate visual information from outside their receptive fields. We examined the synaptic physiology of the horizontal pathway in slices of the cat's striate cortex and found that activating lateral fibers produced both excitation and inhibition.
\end{abstract}

We recorded the postsynaptic responses of identified pyramidal cells in layer $2+3$ of area 17 to electrical shocks applied at three sites: in the home column of the impaled neuron either in layer $2+3$ or 4 , or at a lateral distance of 0.9-3 $\mathrm{mm}$ in layer $2+3$. Within the home column, suprathreshold stimuli produced compound EPSPs with action potentials, followed by fast, GABA $A_{A}$ ergic IPSPs and a slower, GABA $_{B}$ ergic IPSP. For the distant stimulating site, the threshold response was an EPSP. Stronger shocks frequently evoked a disynaptic, GABA A $_{A}$ ergic IPSP that truncated the EPSP and could dominate the postsynaptic response. At the resting potential, the horizontally evoked EPSP was too small to elicit spikes. With depolarization of the membrane, however, it grew several hundred-fold. This amplification was blocked by $\mathrm{N}$-(2,6-dimethylphenylcarbamoylmethyl)triethylammonium bromide (QX-314), but not by 2-amino-5-phosphonovalerate (APV), indicating that it was mediated by $\mathrm{Na}^{+}$ channels, rather than by NMDA receptors.

We propose that the horizontal connections provide the means for stimuli outside the receptive field to modulate activity elicited within its confines. The voltage-dependent enhancement of the laterally evoked EPSP may explain why stimulating the surround by itself fails to drive cells but can facilitate their response to stimuli within the receptive field. The ability to initiate disynaptic inhibition from lateral sites shows that recruiting appropriate groups of horizontal fibers can also have a suppressive effect. Thus, the effect of horizontal input is state dependent, with the size and sign of the laterally evoked response changing according to the balance of converging inputs.

\footnotetext{
Reccived Oct. 17, 1990; rcviscd Jan. 24, 1991; acceptcd Jan. 30, 1991.

We are grateful to Torsten N. Wiesel for his support throughout the project and for his careful and critical comments on the manuscript. We also thank Kaare Christian for help with computers, Peter Peirce for photography, and Shari Zagorski for technical assistance. These experiments were funded by NIH Grants EY06010 to J.A.H. and NS22789, National Science Foundation Grants BNS8918951 and BNS8351738, and an award from the Rita Allen Foundation to C.D.G.

Correspondence should be addressed to Judith A. Hirsch, Laboratory of Neurobiology, Box 138, The Rockefeller University, 1230 York Avenue, New York, NY 10021.

Copyright (C) 1991 Society for Neuroscience $0270-6474 / 91 / 111800-10 \$ 03.00 / 0$
}

The cerebral cortex transforms information coming from the thalamus and other cortical areas by means of a stereotyped set of vertical and horizontal connections. In the primary visual cortex, cells with shared receptive fields are connected by interlaminar, vertical collaterals and are arranged in radially oriented columns (Lorente de Nó, 1944; Hubel and Wiesel, 1963). Another, more recently discovered set of connections are longrange, clustered, horizontal projections that course for $6-8 \mathrm{~mm}$ within a single layer (Gilbert and Wiesel, 1979, 1983, 1989; Rockland and Lund, 1983; Martin and Whitteridge, 1984). These extensive collaterals link columns with shared orientation preference and enable recipient cells to integrate information over a larger visuotopic area than the "classical" receptive field, that rcgion in which a simple stimulus can evoke activity (Ts'o et al., 1986; Gilbert and Wiesel, 1989). The current study explores the synaptic physiology of the horizontal, or "lateral," pathway, in order to help learn how information from outside the classical receptive field can modulate a neuron's response.

Stimulation of the surround has both inhibitory and excitatory influences on responses evoked from the central part of the receptive field (Allman et al., 1985; Nelson and Frost, 1985; Orban et al., 1987; Wiesel and Gilbert, 1989; Gilbert and Wiesel, 1990). These influences could be mediated by lateral inputs (Wiesel and Gilbert, 1989; Gilbert and Wiesel, 1990). Though the horizontal collaterals arise mainly from pyramidal cells and usually contact other pyramids, as many as $20 \%$ of the postsynaptic targets are smooth cells (Kisvárday et al., 1986; McGuire et al., 1991). Thus, stimulating horizontal fibers could have disynaptic inhibitory effects as well as direct excitatory actions. Cross-corrclation analysis indicatcs that lateral inputs are primarily excitatory. This is not, however, a technique well suited to resolve inhibitory interactions (Ts'o et al., 1986).

In the present study, we recorded intracellularly from brain slices to examine the physiological properties of the synapses in the horizontal pathway. Intracellular electrodes provide a means of measuring synaptic efficacy and of characterizing excitatory and inhibitory input. Furthermore, surgical and pharmacological isolation of various presynaptic pathways is more easily achieved in vitro than in situ. Our results provide insights about the excitatory and inhibitory mechanisms underlying the role that horizontal connections play in visual cortical processing.

\section{Materials and Methods}

Anesthesia and surgery. Twenty-nine adult cats, $2-4 \mathrm{~kg}$, were first anesthetized with an intramuscular injection of ketamine $(10 \mathrm{mg} / \mathrm{kg})$, after which anesthesia was maintained with intravenous Pentothal $(20 \mathrm{mg} /$ $\mathrm{kg}$ ). The EKG and temperature were continually monitored; temperature was controlled with a heating pad.

The animal was placed in a stereotaxic device, and the skull overlying the occipital cortices was removed. The dura was incised along the 
anteroposterior axis and reflected to expose the lateral gyrus. A block of the gyrus was then cut with a scalpel and removed with a spatula. The excised tissue was placed in oxygenated artificial cerebral spinal fluid (ACSF) for several minutes until slices were made.

Preparation and maintenance of slices. After gently removing the pia from the gyrus, the block was placed on a slab of agar, usually with the medial bank facing upwards, and transferred to a tissue slicer modeled after a guillotine (Katz, 1987). This apparatus carries a rack containing about 50 gold-plated tungsten wires, $20 \mu \mathrm{m}$ in diameter, that are arranged in parallel $400 \mu \mathrm{m}$ apart. The rack is suspended by a springloaded carrier and moves quickly through the tissue when the spring is released, producing up to 50 coronal slices.

The slices were placed in ACSF, separated with a fine brush, and moved one by one to a closed interface chamber held at $25-30^{\circ} \mathrm{C}$, where they were kept for 2-28 hr. Their lower surfaces rested on nylon nets placed over a bath containing ACSF, and their upper surfaces were exposed to an atmosphere of $95 \% \mathrm{O}_{2}$ and $5 \% \mathrm{CO}_{2}$ saturated with $\mathrm{H}_{2} \mathrm{O}$.

For recording, a slice was submerged in a glass-bottomed chamber with a volume of $0.4 \mathrm{ml}$ and was held stable by a weighted nylon net. Control and test solutions were perfused through the chamber at a rate of $\approx 0.5 \mathrm{ml} / \mathrm{min}$ and heated to $34-35^{\circ} \mathrm{C}$. The chamber was illuminated from below and viewed from above through a dissecting microscope. In some experiments the superficial layers of the slices were isolated by undercutting with fragments of razor blade before the net was put in place.

Recording and stimulation. Intracellular electrodes were pulled from borosilicate, capillary glass tubing with a $1.2-\mathrm{mm}$ outer diameter and $0.6-\mathrm{mm}$ inner diameter. Electrodes had resistances of 40-100 M $\mathrm{M}$ wen filled with the electrolyte. Transmembrane voltage was monitored, and intracellular current was delivered through a bridge circuit and displayed on an oscilloscope and computer terminal. Data were digitized on line and stored on videotape and on disk for futủre analysis.

Electrical stimuli consisted of shocks lasting from 50 to $150 \mu \mathrm{sec}$, of between 1 and $100 \mathrm{~V}$, that were delivered at $0.1 \mathrm{~Hz}$ through two sharpened, insulated tungsten wires with a tip separation of $\approx 50 \mu \mathrm{m}$.

Solutions. The standard ACSF contained, in mм, $\mathrm{NaCl}, 125 ; \mathrm{KCl}, 5$; $\mathrm{NaHCO}_{3}, 126 ; \mathrm{CaCl}_{2}, 2.4 ; \mathrm{MgCl}_{2}, 1.3 ;$ and dextrose, 10 . It was saturated with $95 \% \mathrm{O}_{2} / 5 \% \mathrm{CO}_{2}$ and adjusted to $\mathrm{pH} 7.4$. All externally applied drugs were dissolved in the ACSF and delivered in the bath. The 2-hydroxy-saclofen and the 5-amino-phosphonovalerate (APV) were from Tocris Ltd.; the bicuculline methiodide (BMI) was from Research Biochemical Inc.

The recording electrodes were filled with $3-4 \mathrm{M}$ potassium acetate (KAc; $\mathrm{pH}, 7.2$ ). At times, the electrode tips were backfilled with $2 \%$ biocytin (Molecular Probes) in KAc before the shanks were filled with the electrolyte. The biocytin labeled the cells during recording, and they could then be identified after histological processing. For some experiments, electrode tips were backfilled with $100 \mathrm{~mm} N$-(2,6-dimethylphenylcarbamoylmethyl)triethylammonium bromide (QX-314; gift of Astra Pharmaceuticals) dissolved in $3 \mathrm{M}$ KAc.

Histology. The tissue containing biocytin-labeled cells was processed using a modification of the technique described in Horikawa and Armstrong (1988). Briefly, slices were fixed overnight in $4 \%$ paraformaldehyde, cut into $70-\mu \mathrm{m}$ sections with a freezing microtome, and rinsed twice with PBS. The sections were then incubated for $45 \mathrm{~min}$ in PBS containing $0.25 \%$ Triton and $2 \%$ BSA. After rinsing in PBS with $2 \%$ BSA, they were incubated in avidin-HRP (Vector Laboratories; diluted $1: 100$ in PBS and 2\% BSA) for $2 \mathrm{hr}$ at room temperature or overnight at $4^{\circ} \mathrm{C}$. The tissue was then washed in PBS $(3 \times 15 \mathrm{~min})$ and incubated for $1 \mathrm{hr}$ in $0.05 \%$ diaminobenzidine (DAB) in PBS. Hydrogen peroxide $(0.3 \%)$ was then added at a ratio of 1:100 to the DAB solution. About 15 min later, the sections were rinsed three times in PBS and were mounted, dehydrated, and coverslipped.

\section{Results}

The results presented here were obtained from impalements that lasted from $20 \mathrm{~min}$ to $6 \mathrm{hr}$; our sample includes intracellular recordings from 61 neurons. The average input resistance was $41 \pm 16 \mathrm{M} \Omega$ (mean $\pm \mathrm{SD}$ ), and the average resting potential was $77 \pm 7 \mathrm{mV}$. Of the 18 cells labeled with dye, all were pyramids; no smooth stellate cells were filled. All the stained cells had action potentials whose width at half the maximum amplitude was $\geq 1 \mathrm{msec}$. Unlabeled neurons were identified physiologically either as pyramids if their action potentials lasted $\geq 1 \mathrm{msec}$ at half-height or as smooth cells if their spikes were $\leq 0.6 \mathrm{msec}$ at half-height, according to the criterion of Schwartzkroin and Mathers (1978) and others (McCormick et al., 1985; Naegele and Katz, 1990).

The top right panel in Figure 1 shows a schematic diagram of a typical slice. The recording electrode was placed in layer $2+3$ while a stimulating electrode was placed at one of three sites: in near vertical alignment (within $50 \mu \mathrm{m}$ ) with the site of impalement, either in the same layer or in layer 4 , or at a horizontal displacement of $800 \mu \mathrm{m}$ to $3 \mathrm{~mm}$ in layer $2+3$. The records were obtained from a single physiologically identified pyramidal cell. Stimulation from a distance (Fig. $1 A$ ) consisted only of an EPSP. In contrast, the synaptic potentials elicited in vertical register with the recording clcctrode (Fig. $1 B, C$ ) comprised a compound EPSP with action potentials followed by early, fast and then late, slow inhibitory potentials. While the vertical responses evoked from layer $2+3$ (Fig. $1 B$ ) were less robust than those from layer 4 (Fig. $1 C$ ), they were qualitatively similar.

The recordings in Figure 2 were made from physiologically identified pyramidal cells in three preparations where the superficial layers had been undercut to remove ascending inputs. Figure 2, $A$ and $B$, illustrates both the excitatory and inhibitory extremes of the range of responses to stimuli at a distance ("far"; see Fig. 1, site A, upper right). The traces in Figure $2 A$, top to bottom, show responses that remained largely excitatory as stimulus strength was raised from threshold to the maximum. The EPSP recorded at threshold was small, less than $2 \mathrm{mV}$, and grew gradually over the span of shock voltages; three examples are shown in Figure $2 A$. Even at the highest stimulus voltage, the EPSPs were too small to elevate the membrane from the resting potential to the threshold for firing (not shown).

For 17 out of 29 cells in the undercut preparations, stimulation at a distance evoked inhibition as well as excitation (Fig. $2 B$ ); the rest showed only excitation. The same slice could contain neurons with both types of response. Though for the cell in Figure $2 B$ the threshold response was mainly excitatory, increasing the stimulus voltage evoked an early, fast IPSP that carved into the EPSP and eventually dominated the postsynaptic response at high shock strengths.

The averaged value of the latency of all the remotely evoked EPSPs divided by the distance from the stimulus site was 3.5 $\pm 1.2 \mathrm{msec} / \mathrm{mm}$. Because this value includes both the synaptic delay and spike initiation time (totaling $\approx 0.6-0.8 \mathrm{msec}$ ), it probably underestimates the conduction velocity of the horizontal fibcrs. Of 10 cells for which the beginnings of both the excitatory and inhibitory potential were clearly distinguished by a steep slope, the lag between the EPSP and IPSP, measured at the maximum stimulus strength, was $2.6 \pm 0.9 \mathrm{msec}$. This delay suggests that inhibition was, at the minimum, disynaptic.

"Far" stimuli failed to evoke late IPSPs, unless, as will be shown later, fast inhibition was blocked with bicuculline. When serial EPSPs were present during perfusion of the standard ACSF, the early EPSP was able to follow stimulation at high frequency, $1.7 \mathrm{~Hz}$, while the later ones were not, indicating that the first EPSP was monosynaptic while the subsequent ones were di- or multisynaptic.

When the stimulating electrode was placed within $50 \mu \mathrm{m}$ of the impalement ("near"; see Fig. 1, site B, upper right), weak shocks elicited an EPSP (Fig. 2C). At slightly higher stimulus voltages, the EPSP was cut short by a fast IPSP, as in Figure 
A
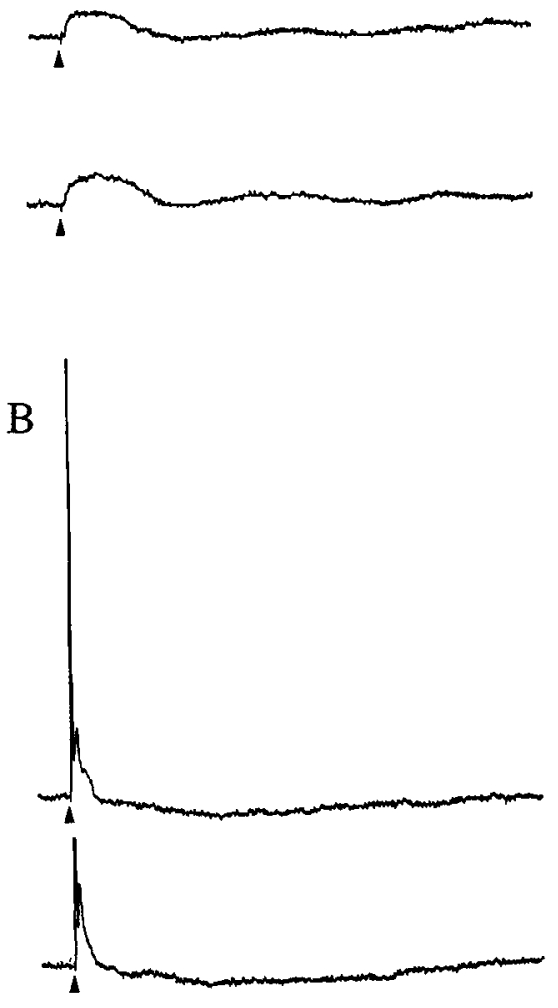
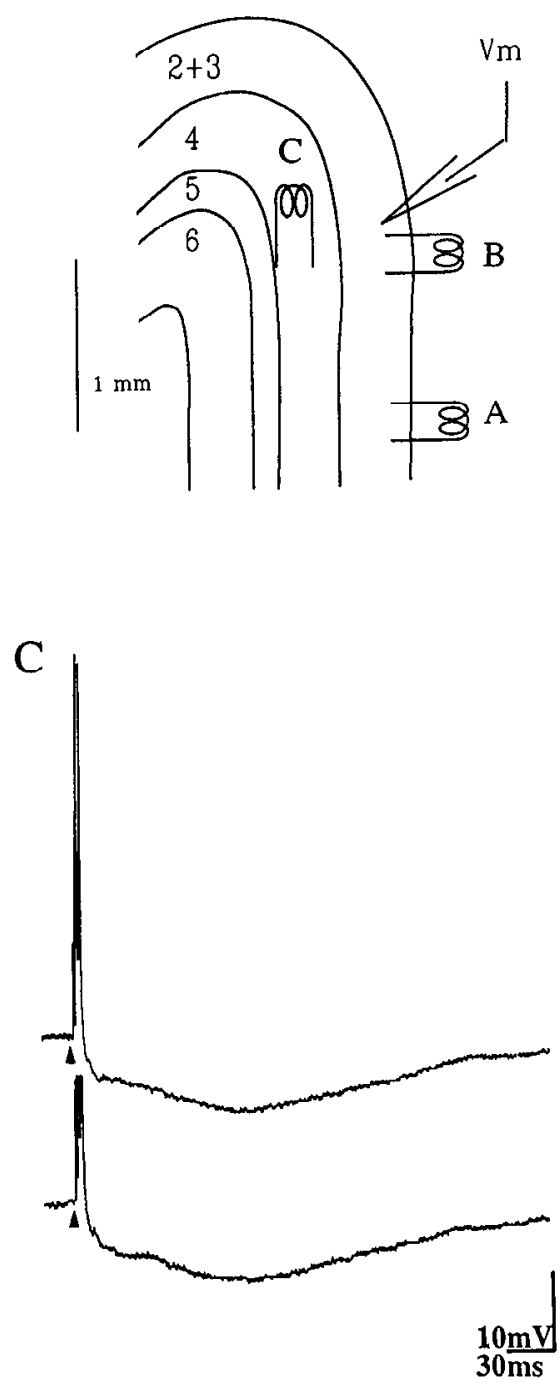

$\mathrm{m}$

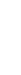

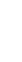

Figure 1. Synaptic potentials recorded from a single cell in layer $2+3$ following stimulation of various sites. A schematic diagram of the preparation is shown in the upper right. Traces show EPSP evoked by a shock to layer $2+3$, $\approx 900 \mu \mathrm{m}$ away from the stimulating electrode (site $A$ ) and EPSPs and fast and slow IPSPs following a shock to layer $2+3,50 \mu \mathrm{m}$ away (site $B$ ) and from layer $4,1 \mathrm{~mm}$ below the recording electrode (site $C$ ). Two traces are shown for each stimulus condition $(A-C)$, and action potentials in the lower traces are cropped. The membrane voltage was depolarized to $-62 \mathrm{mV}$ from its resting potential of $-80 \mathrm{mV}$ during the recording in order to visualize IPSPs. $A r$ rowheads mark the stimulus artifact. 
A

low

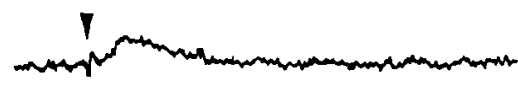

Far

B

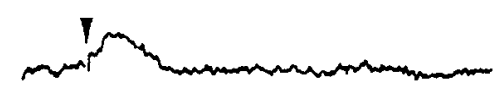

medium

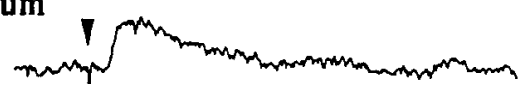
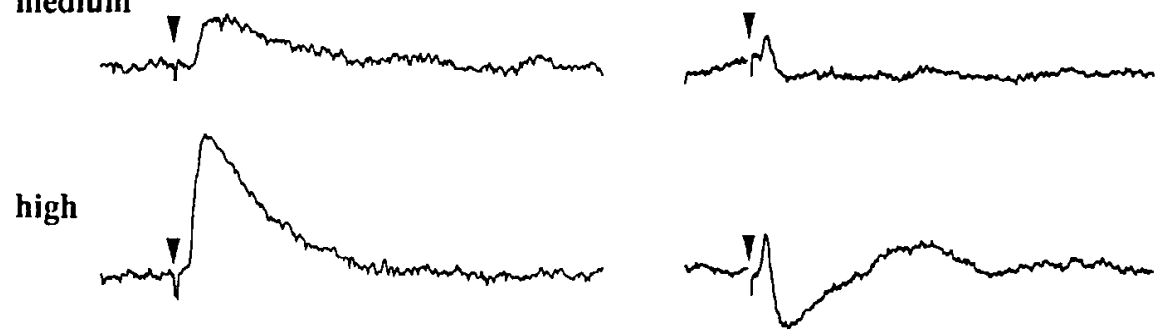

C

Near

low
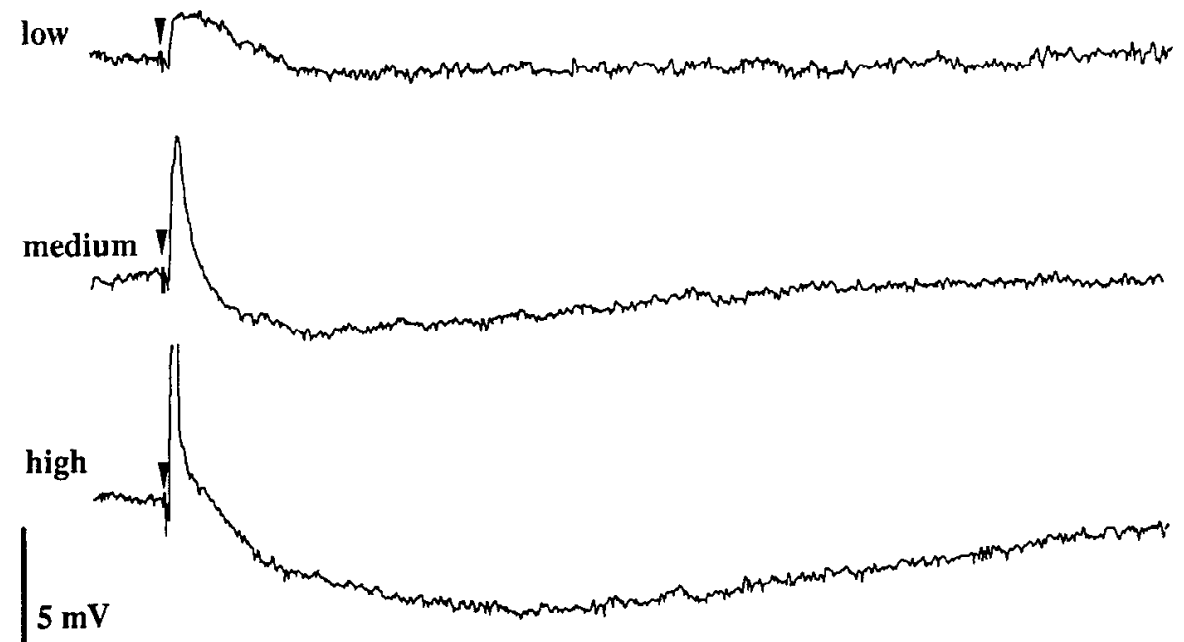

$20 \mathrm{~ms}$

Figure 2. Synaptic responses measured from the undercut layer $2+3$ when the stimulating electrode was $1.2 \mathrm{~mm}$ $(A, B)$ or $50 \mu \mathrm{m}(C)$ away from the micropipette. Each trace is the average of three trials. $A$, Graded EPSPs recorded from a ccll whose rcsponse to horizontal inputs was primarily excitatory. $B$, Synaptic response of a cell whose response to horizontal input also included a graded fast IPSP at stimulus voltages above threshold. $C$, EPSPs and higher-threshold fast and slow IPSPs evoked from a site near the impaled cell; in the bottom trace the response included an action potential, which is cropped. The recordings in each panel were made from three separate cells. The membrane potential was depolarized from -76 to $-58 \mathrm{mV}$ for $A$, from -77 to $-65 \mathrm{mV}$ for $B$, and from -82 to $-60 \mathrm{mV}$ for $C$. The voltage ranges of the shocks used to stimulate the cells in this figure were as follows: low, 5-15 $\mathrm{V}$; medium, 25-50 V; high, 75-100 V. Arrowheads mark the stimulus artifact.
We next examined the participation of NMDA receptors in the laterally evoked response. These are of particular interest because their activation correlates with long-term modifications in synaptic strength (Kauer et al., 1988). The traces in Figure 4 were recorded from a labeled pyramidal cell bcfore (Fig. $4 a$ ), during (Fig. $4 b$ ), and after (Fig. 4c) the inclusion of $30 \mu \mathrm{M} \mathrm{D-APV,}$ an antagonist of NMDA receptors (Watkins and Evans, 1981) in the bath. The APV caused a slight decrease in the size of the EPSP, but did little to reduce its enhancement by depolarization $(n=4)$. The size of the voltage-enhanced EPSP shown after removal of the drug is smaller than it was at first, probably because the input resistance of the cell had decreased during recording. In sum, at potentials below the threshold for firing, it appears that $\mathrm{Na}^{+}$currents are sufficient to explain the increase in the EPSPs' amplitude with membrane voltage, with little or no contribution from currents gated by NMDA receptors.

\section{Analysis of laterally evoked inhibition}

There is diversity among receptors mediating IPSPs as well as EPSPs. In cortex, $\mathrm{GABA}_{\mathrm{A}}$ receptors mediate fast, chloride-de- pendent IPSPs, and $\mathrm{GABA}_{\mathrm{B}}$ receptors transduce longer-lasting IPSPs that rely on increased conductance to $\mathrm{K}^{+}$(Newberry and Nicoll, 1985; Connors et al., 1988; Dutar and Nicoll, 1988a,b). We assayed for the contribution of both subtypes of receptor to the laterally evoked IPSPs by applying selective antagonists to the slices. The recordings displayed in Figure 5 were obtained from a physiologically typed pyramid. Each pair of traces shows two individual trials under the conditions labeled at the upper right. In the control medium, stimulation of lateral inputs evoked the small EPSP followed by a weak, fast IPSP (Fig. 5a). Adding a selective antagonist of $\mathrm{GABA}_{\mathrm{A}}$ receptors, BMI $(25 \mu \mathrm{M})$, to the bath removed the fast IPSP from the cell and revealed a large burst followed by a slow hyperpolarization (Fig. $5 b ; n=4$ ). An antagonist of $\mathrm{GABA}_{B}$ receptors (Kerr et al., 1988), 2-hydroxysaclofen $(0.25-0.5 \mathrm{~mm})$, suppressed the afterhyperpolarization, indicating that it was produced synaptically and that it was a slow IPSP (Fig. $5 c ; n=2$ ). The residual afterhyperpolarization that remained in 2-hydroxy-saclofen was likely a product of intrinsic, nonsynaptic currents. As shown in the inset (Fig. $5 c$ ), firing produced by injection of depolarizing current was followed 
A
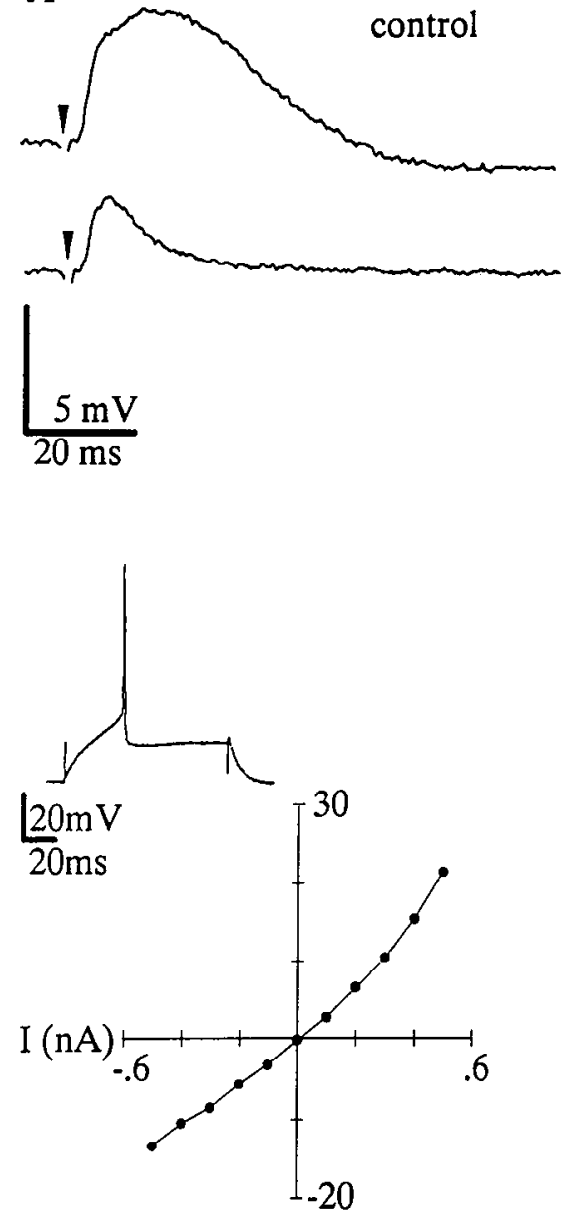

$\triangle \mathrm{V}(\mathrm{mV})$
B

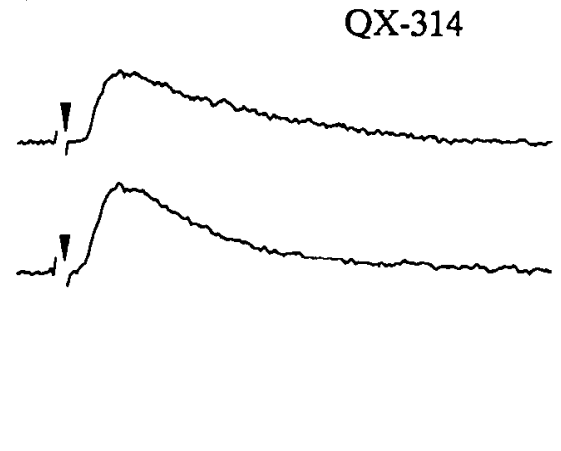

Figure 3. QX-314 abolished the voltage-dependent enhancement of the lateral EPSP. The upper trace in each of the top panels is the average of three trials recorded when the membrane was depolarized by $15 \mathrm{mV}$, and the lower trace is averaged from trials at rest. For the control cell, depolarization increased the size of the EPSP threefold $(A)$, but when QX-314 was injected in another neuron, the size of the EPSP was reduced by depolarization. Arrowheads mark the stimulus artifact. The bottom panels show the action potentials and current-voltage relationships of the two neurons. Both cells identified as pyramids in layer 2 . The resting potentials of the cclls on the right and left were -75 and $-79 \mathrm{mV}$, respectively. by a similar hyperpolarization. The effects of both drugs were reversible (Fig. 5d,e). This experiment, as well as the results shown in Figure 2, suggests that while both types of receptors are present in the undercut layers, fast $\mathrm{GABA}_{\mathrm{A}}$ ergic inhibition was primarily evoked by lateral inputs.

The large bursts produced when fast inhibition was blocked contained polysynaptic EPSPs, as illustrated in Figure 6, obtained from a physiologically classified pyramidal cell. Thus, fast inhibition strongly limits the effects of horizontal inputs. The threshold response in the normal saline was a small EPSP (Fig. 6a). After superfusion with BMI, the strength of the shock required to evoke a synaptic potential dropped from $70 \mathrm{~V}$ (Fig. $6 a$ ) to $12 \mathrm{~V}$ (Fig. $6 b$ ), and the threshold response consisted of a train of EPSPs occurring at long latency. As stimulus voltage was raised (Fig. $6 c, d$ ), the latency of the burst shortened until, at $70 \mathrm{~V}$, the rising phase of the original, monosynaptic EPSP was coincident with that of the burst. The shortening of latency with stimulus intensity implies that the excitatory interneurons are excited more rapidly as larger numbers of convergent inputs are activated. Possibly the appearance of the long slow IPSP, as seen in the last figure, occurred because GABAergic interneurons were also more strongly excited. The traces shown in this figure were recorded at rest to emphasize the EPSPs. Consequently, the IPSPs were not visible because the membrane voltage was below or near their reversal potentials.

The traces in all the previous figures were obtained from cells that were identified as pyramidal on either physiological or anatomical grounds. In rare instances, we recorded from cells that we physiologically classified as interneurons; the responses of these cells to lateral input were very different from those typically exhibited by pyramids. Recordings from a presumed interneuron are shown in the top rows of Figure 7, and responses obtained from a stained pyramidal cell are shown below; each pair of traces shows two trials of the same stimulus. As the shock voltage increased, the interneuron fired progressively harder, showing the pattern of increasing activity that one would expect to generate the intensifying inhibition characteristically shown by pyramidal cells as stimulus strength is raised.

\section{Discussion}

Our results show that horizontal connections can inhibit as well as excite their postsynaptic targets. In the following paragraphs, we discuss these laterally evoked responses in terms of what is known about their underlying anatomy and how they compare with synaptic potentials recorded in various cortical areas. Also, 
we consider our findings in the context of those from experiments that have explored horizontal connections with visual stimuli, in vivo.

\section{Source of the synaptic potentials}

The responses evoked from sites in vertical register with the impaled cell probably arose from the home column of the impaled neuron, while the distant sites were on the order of one to three hypercolumns away. A hypercolumn is a segment of cortex containing a full complement of orientation or ocular dominance columns and in the cat is approximately $1 \mathrm{~mm}$ wide (Hubel and Wiesel, 1963; Löwel et al., 1987, 1988). The terminals of the horizontal collaterals are distributed in clusters and connect columns of similar orientation preference (Gilbert and Wiesel, 1979, 1983, 1989; Martin and Whitteridge, 1984; Ts'o et al., 1986). As a consequence, one might expect that EPSPs produced by lateral inputs would arise only from spatially discrete loci arrayed at a periodicity roughly equal to the width of a hypercolumn. Our stimulus was a shock, however, so it could activate fibers of passage as well as the somata underneath the electrodes, making it difficult to identify the columns where the inputs originated. We are currently designing experiments to study the specificity of the horizontal inputs in the slice preparation.

The most likely source of the synaptic potentials we recorded in the undercut preparations was input intrinsic to layers $2+3$ of area 17. Callosal terminals are largely confined to the area 17/18 border (Hubel and Wiesel, 1967; Shatz, 1977; Innocenti, 1980), and most of the other inputs to the upper layers, such as thalamic afferents (LeVay and Gilbert, 1976; Humphrey et al., 1985) or the diffuse projections from the brainstem (Morrison et al., 1982), would have been transected. Descending projections from extrinsic cortical regions, areas 18 and 19 , for example, may course through the superficial laminae (Creutzfeldt et al., 1977; Tigges et al., 1981; Rockland and Virga, 1989), but are sparse relative to the fibers originating in area 17. Intracellular injections show that the majority of pyramidal cells, themselves accounting for $80 \%$ of the cellular population in layer $2+3$, extend long-range collaterals (Gilbert and Wiesel, 1979, 1983, 1985; Martin and Whitteridge, 1984; Callaway and Katz, 1990).

\section{Excitation}

The laterally evoked EPSP was too weak to trigger action potentials, unless the membrane was depolarized from rest by the injection of current through the microelectrode. In view of previous studies, the small size of the lateral EPSP is not surprising, and many synchronously active fibers are probably required to exert even a small effect. The axonal arbors of the long-range collaterals are not nearly as dense as the intracolumnar terminal fields (Gilbert and Wiesel, 1979, 1983) and make few contacts on each postsynaptic cell (Kisvárday et al., 1986, Gabbott et al., 1987; McGuire, 1991). Comparison of cross-correlation studies of inter- versus intracolumnar connections indicates that the lateral ones are about an order of magnitude weaker (Toyama et al., 1981a,b; Ts'o et al., 1986; Toyama, 1988). Taken together, our own evidence and that of the earlier anatomical and physiological studies suggest that the role of horizontal connections is likely to modulate rather than generate activity within a given column.
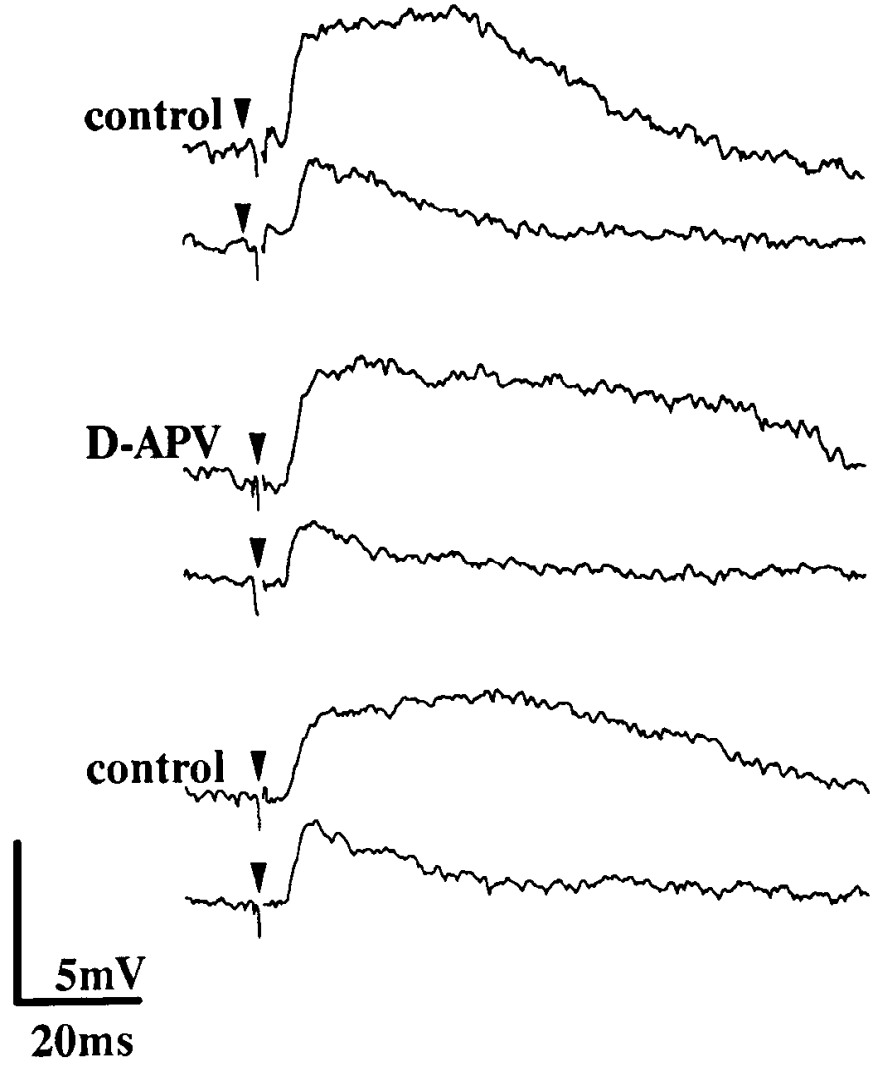

Figure 4. APV had little effect on the voltage-dependent enhancement of the lateral EPSP. Each trace is the average of three trials; the top traces were collected when the membrane was depolarized by $18 \mathrm{mV}$, and the bottom traces were taken at rest $(-82 \mathrm{mV})$. The application of $30 \mu \mathrm{M}$ D-APV reversibly reduced the size of the EPSP but did not prevent its enlargement by depolarization. This cell was identified as a pyramid in layer 2. Arrowheads mark the stimulus artifact.

\section{Voltage dependence of the lateral EPSP}

An important feature of the EPSP produced by horizontal fibers was its state dependence: it increased in size as the membrane potential was raised from rest to near the threshold for spontaneous firing. Voltage-dependent EPSPs have been reported in earlier cortical studies where synaptic responses were apparently evoked from the home column, that is, from sites near or vertically aligned with the recording micropipette (Staftstrom et al., 1985; Jones and Baughman, 1988; Thomson et al., 1988; Sutor and Hablitz, 1989a,b; Artola and Singer, 1990). In most of these reports, the early EPSPs were enhanced by depolarization, whereas the later ones showed conventional voltage relationships (Sutor and Hablitz, 1989a,b).

From experiments using voltage clamp, injection of QX-314, or application of APV, Sutor and Hablitz $(1989 \mathrm{a}, \mathrm{b})$ found that, in layer $2+3$ of adult rat cortex, $\mathrm{Na}^{+}$currents are the principal source of the augmentation of the carly, intracolumnar EPSP. In contrast, others conclude that application of APV decreases the voltage dependence of that EPSP (Jones and Baughman, 1988; Artola and Singer, 1990). There is agreement with our present work, however, that at rest the NMDA-receptor-mediated component of the cortical EPSP is small (Jones and Baughman, 1988; Shirokawa et al., 1989; Sutor and Hablitz, 1989a,b; Artola and Singer, 1990).

The voltage dependence of the horizontally evoked EPSP is 

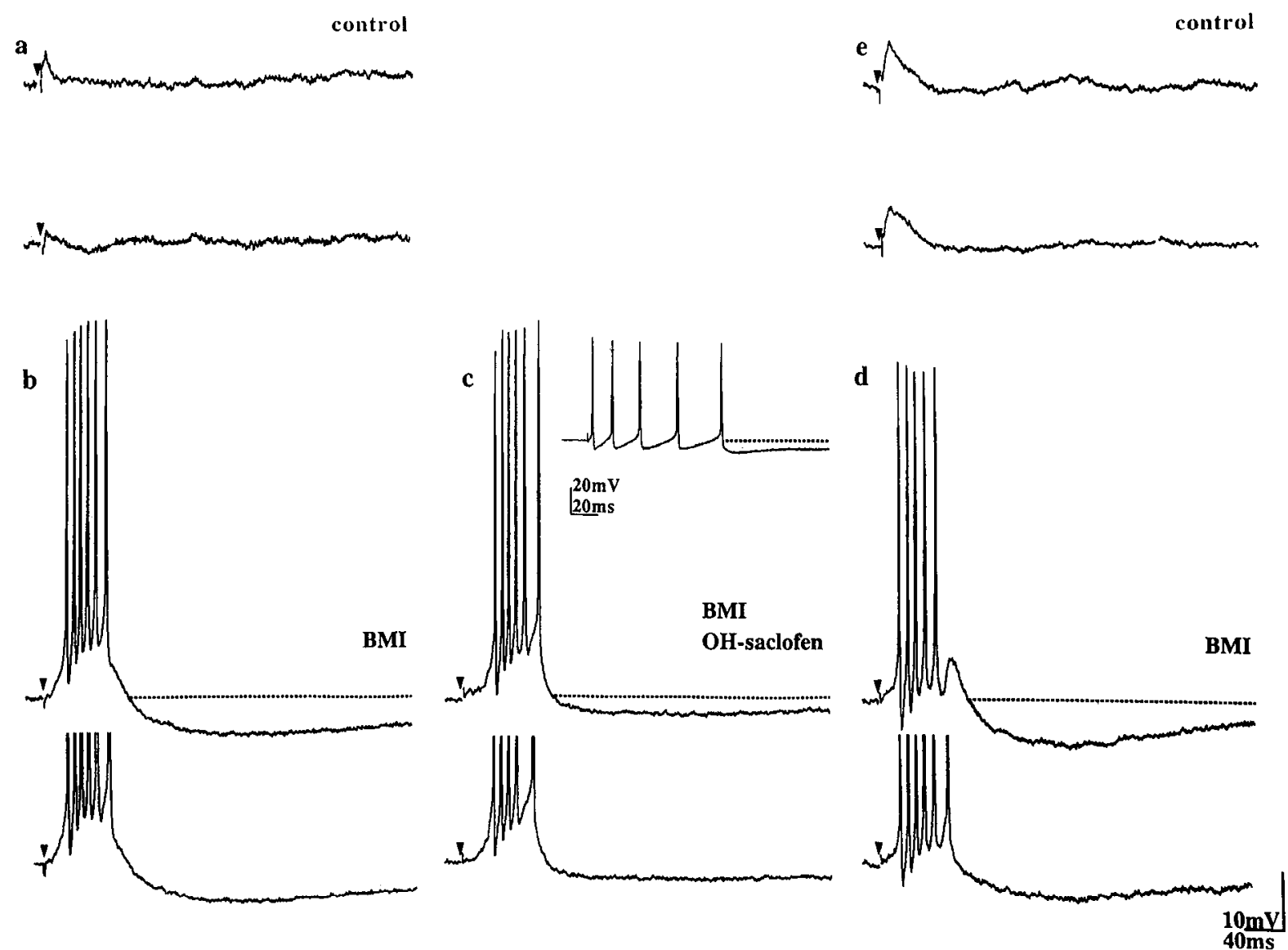

Figure 5. IPSPs mediated by both $\mathrm{GABA}_{\mathrm{A}}$ and $\mathrm{GABA}_{\mathrm{B}}$ receptors were generated by elements intrinsic to the undercut cortex. The fast IPSP (a) was removed by the application of $25 \mu \mathrm{M}$ BMI, yielding an excitatory burst followed by a slow inhibitory potential $(b)$ that was blocked by 0.5 mM 2-hydroxy-saclofen $(c)$. The inset in $c$ shows that an afterhyperpolarization such as that seen when the slow IPSP was blocked could be produced by direct injection of depolarizing current. The effects of both drugs were reversible $(d, e)$. Two traces are shown for each stimulus condition, and action potentials in the lower traces are cropped. The broken lines indicate the baseline in the top traces of $b-d$. The traces were made when the membrane was depolarized from -79 to $61 \mathrm{mV}$. Arrowheads mark the stimulus artifact.

a

$70 \mathrm{VV}$

Figure 6. The excitatory burst generated in hicuculline was produced by multisynaptic EPSPs. When fast inhibition was blocked, the threshold stimulus dropped from nearly $70 \mathrm{~V}(a)$ to $12 \mathrm{~V}(b)$, and the threshold response changed from a monosynaptic EPSP at shori $(3.6 \mathrm{msec}$ ) latency to large, suprathreshold potential at long $(35 \mathrm{msec})$ delay. Increasing the shock strength shortened the latency of the burst $(c)$ until it overlapped the monosynaptic EPSP at the original threshold voltage ( $d$; trace in $a$ shown here as a broken line). Each trace is the average of three trials recorded while the membrane was at rest, $-83 \mathrm{mV}$. Arrowheads mark the stimulus artifact.

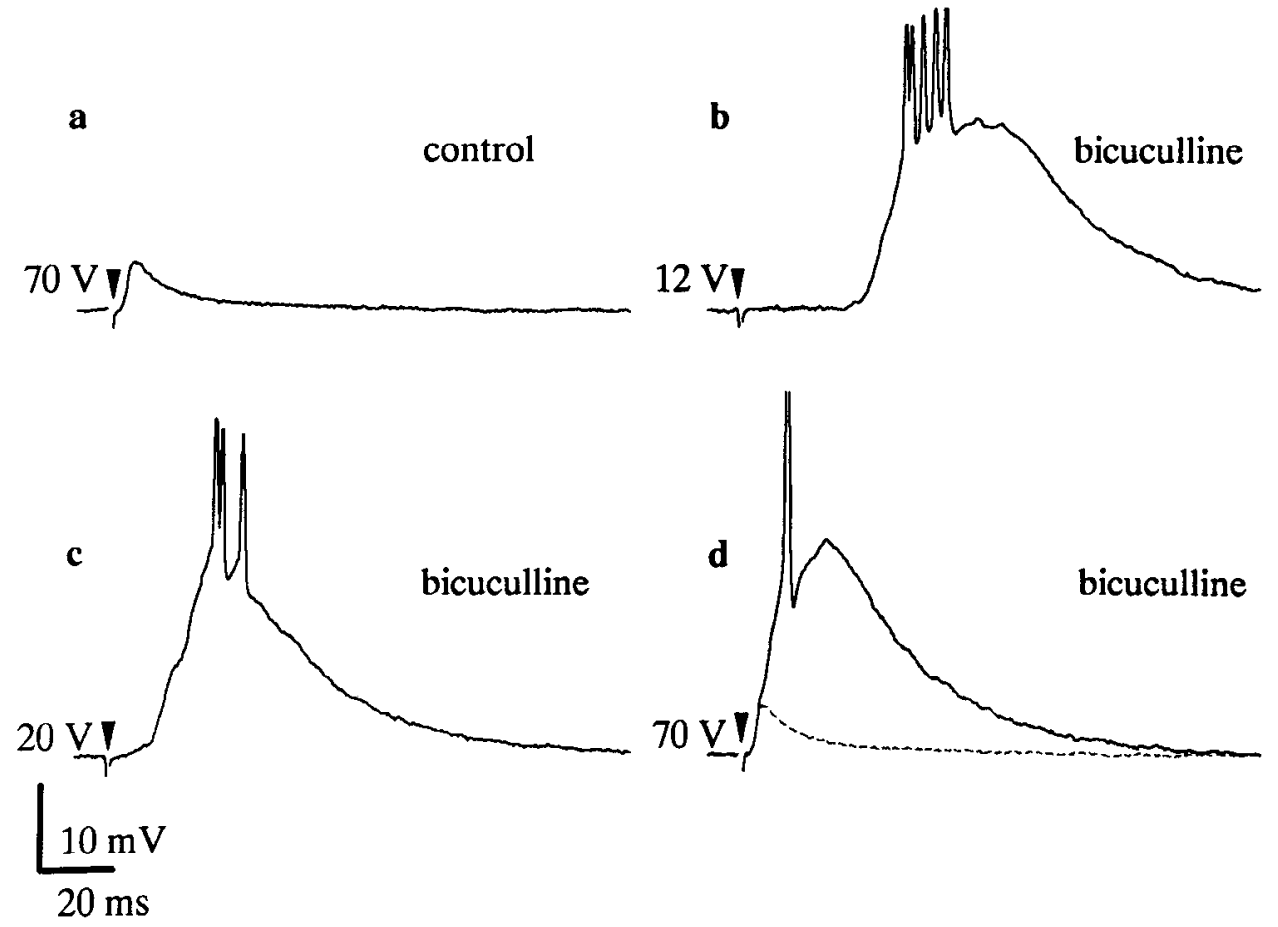



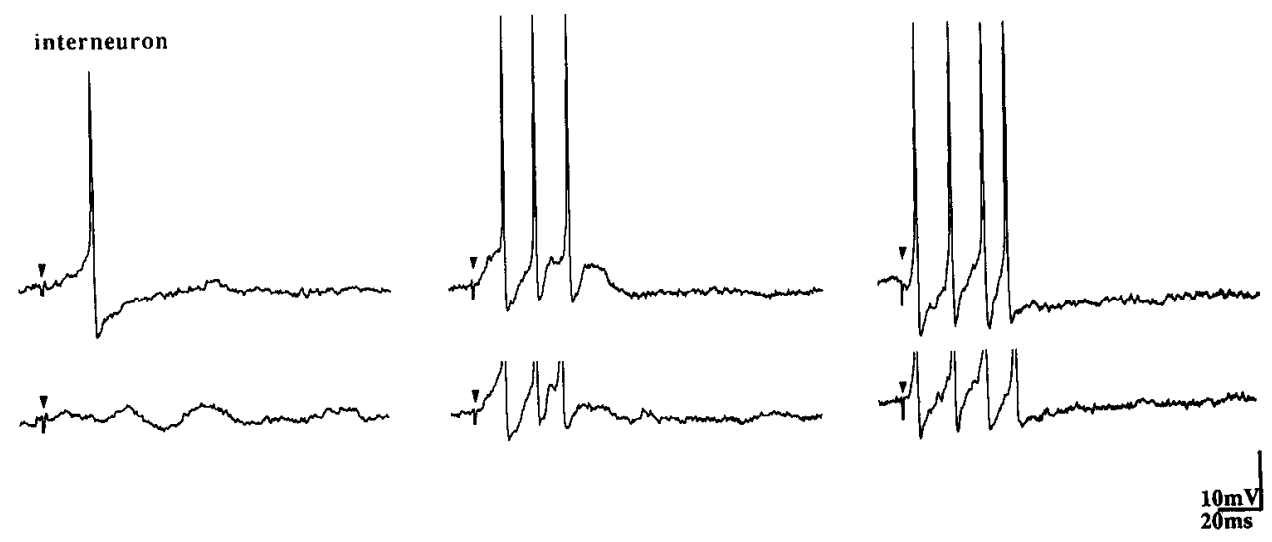

pyramid

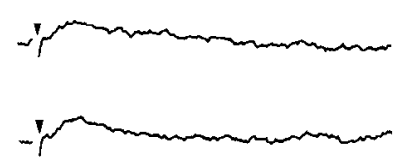

low

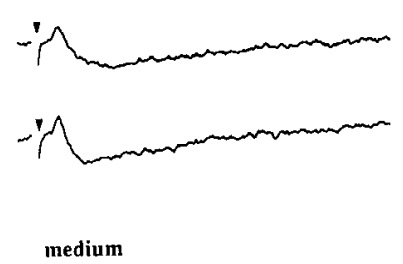

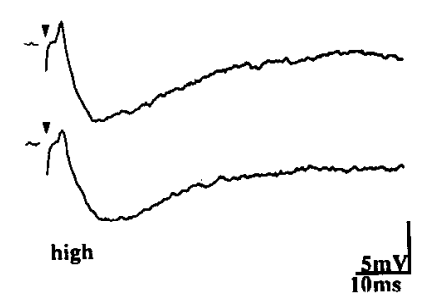

Figure 7. Compared response of a presumed inhibitory interneuron and a pyramidal cell to lateral input. The top traces made from a presumed interneuron show that increasing the stimulus strength evokes progressively stronger excitation. The reverse situation is true for the pyramidal cell; stronger stimuli shift the balance of the synaptic input towards inhibition. Traces are displayed as in Figure 1; the membrane potential was depolarized from -63 to $-60 \mathrm{mV}$ for the top traces and from -85 to $-62 \mathrm{mV}$ for the bottom traces. Arrowheads mark stimulus artifact. not obviously different from the monosynaptic, intracolumnar ones, though it is unclear if the underlying mechanisms are the same. The meager size of the lateral EPSP, however, could make it particularly dependent on intrinsic depolarizing conductances or on additional synaptic excitation to bring the postsynaptic cell to fire. Because the amplification of the lateral EPSP does not appear to require NMDA receptors, one need not equate this behavior with the long-term changes associated with the NMDA receptor, at least within the voltage range tested here (cf. Hestrin et al., 1990). The voltage dependence may simply provide a means whereby the effect of the horizontal inputs would be subject to the context of levels of convergent activity.

\section{EPSPS in the presence of bicuculline}

In our preparations, compound EPSPs evoked by horizontal stimuli were infrequent, but they always appeared when fast inhibition was blocked by bicuculline. Field potentials recorded from layer $2+3$ in cat and rat have shown that activity can propagate horizontally for millimeters when inhibition is pharmacologically reduced (Chervin et al., 1988). Our results suggest that this propagation can be aided by elements within layer $2+3$.

\section{Inhibition}

The marked role of inhibition in synaptic interactions within the superficial layers is perhaps unexpected given the statistic that no more than $20 \%$ of the terminals of layer 3 pyramids contact inhibitory cells (Kisvárday et al., 1986; McGuire et al., 1991), yet many factors can influence the strength of connections, such as the distribution of presynaptic contacts, the electrical characteristics of the postsynaptic cell, and the arrangement of its boutons on the next neurons in the synaptic net. In fact, smooth stellate cells are more densely innervated and receive proportionately fewer symmetric, presumably inhibitory, contacts than do pyramidal cells (McGuire et al., 1991). Furthermore, in cortex, GABAergic cells fire more rapidly per unit increase in applied current than do pyramidal cells, a behavior that apparently reflects an actual difference in excitability between the two types of neuron in their balances of $\mathrm{K}^{+}, \mathrm{Na}^{+}$, and $\mathrm{Ca}^{2+}$ channels (Schwartzkroin and Mathers, 1978; McCormick et al., 1985; Giffin et al., 1988; Prince and Huguenard, 1988). Indeed, in the few instances studied, interneurons have a predominantly excitatory response to synaptic input (Fig. 7; McCormick et al., 1985).

Anatomical evidence suggests that single inhibitory neurons have a stronger impact than individual excitatory ones in determining whether or not a given pyramidal target will fire. GABAergic synapses are often placed in a position to yield maximum effect, such as on the dendritic shaft, near the cell body, or at the initial segment (Le Vay, 1973; Fairén and Valverde, 1980; Fairén et al., 1983; Beaulieu and Somogyi, 1990). Also, smooth stellate cells may amplify their inhibitory effect by making more synapses per recipient neuron than do pyramidal cells (Fairén and Valverde, 1980; Somogyi et al., 1983).

From our experiments, we concluded that IPSPs evoked by remote stimuli were mediated by more than one synapse. Because the arbors of most interneurons are confined to an area about 200-300 $\mu \mathrm{m}$ in diameter (Lorente de Nó, 1944; Somogyi et al., 1982; Fairén et al., 1983; Naegele and Katz, 1990), most of the inhibition we saw was probably local. Some basket cells have axons extending for a millimeter or longer (Martin et al., 1983; Somogyi et al., 1983) and possibly could have contributed a monosynaptic inhibitory component that was masked by the EPSP. In some preliminary experiments, however, where the EPSP was pharmacologically blocked, we saw no such component. Last, our results showed that both fast and slow IPSPs could be produced by some type or types of cell intrinsic to the superficial layers.

That only fast, and not slow, IPSPs were evoked by lateral stimuli may have been a matter of the relative strength of synaptic input onto interneurons. The late IPSP is usually found 
to have a higher threshold than the early one (Avoli, 1986; Howe et al., 1987a,b; Dutar and Nicoll, 1988a; cf. Connors et al., 1988). It is possible that the $\mathrm{GABA}_{\mathrm{B}}$ receptors have a lower affinity for $\mathrm{GABA}$ than do the $\mathrm{GABA}_{\mathrm{A}}$ receptors and therefore interneurons must fire rapidly to release enough transmitter to open the $\mathrm{GABA}_{\mathrm{B}}$-linked channels (Newberry and Nicoll, 1985; Dutar and Nicoll, 1988a).

Alternatively, it may be the case that different types of neuron selectively produce either fast or slow IPSPs and that horizontal fibers tend to contact the former. Though the evidence is stronger in the hippocampus (Newberry and Nicoll, 1985) than in the neocortex (Connors et al., 1988), it seems that sensitivity to the $\mathrm{GABA}_{\mathrm{B}}$ antagonist baclofen is greatest in the distal dendrites, whereas responsiveness to $\mathrm{GABA}_{\mathrm{A}}$ antagonists is widesprcad. Pcrhaps some latcral inputs preferentially excite those inhibitory cells, such as basket cells, that synapse on or near the soma (McGuire et al., 1991). Whatever the mechanism, the prevalence of the fast IPSP over the slow one suggests that laterally evoked inhibition can be quickly gated on and off.

\section{Relevance to studies of receptive fields}

Experiments measuring responses to stimuli placed inside and outside the receptive field provide ideas about the role horizontal connections play in visual processing. One finding of these experiments is that stimulating the surround has dual consequences, in some cases causing excitation, and in most, inhibition. When the surround has an excitatory effect, it cannot drive a cell directly but can facilitate the response to stimuli placed inside the receptive field (Allman et al., 1985; Nelson and Frost, 1985; Orban et al., 1987; Wiesel and Gilbert, 1989; Gilbcrt and Wicscl, 1990). A mechanism for this could involve the voltage dependence of the laterally evoked EPSP. The EPSP would be small with illumination of the surround only, but would increase in size as stimuli presented within the receptive field recruited additional depolarizing inputs.

Frequently, the influence of the surround is suppressive (Bishop et al., 1973; Nelson and Frost, 1978; Orban et al., 1987; Wiesel and Gilbert, 1989; Gilbert and Wiesel, 1990). Our results showed that, as increasing numbers of lateral fibers were activated, progressively stronger inhibition was provided. Thus, even though the horizontal collaterals are extended largely by pyramidal cells, which are presumably excitatory, and in turn make a minority of postsynaptic contacts with inhibitory neurons, the remote inhibitory effects observed in vivo could well be generated by the horizontal connections.

Both the facilitatory and the suppressive effects of the surround could stem from the same distant sites since the IPSPs evoked by lateral stimulation are probably of disynaptic, local origin. Because the horizontal connections in area 17 join regions of similar orientation specificity (Ts'o et al., 1986; Gilbert and Wiesel, 1989), the lateral IPSPs and EPSPs might share orientation preference with their targets. Intracellular recordings made in vivo reveal that postsynaptic potentials of both polarities are tuned to the same angle (Ferster, 1986, 1989), and the implication from our studies is that inhibition from remote parts of the visual field would obey a similar rule.

The state dependence of the horizontal connections could be responsible for nonlinear interactions between the lateral and interlaminar inputs and may account for the unusual effects of activating the surround on orientation tuning, such as changes in preferred orientation or tuning bandwidth (Gilbert and Wiesel, 1990). One may speculate that the modulatory effects of the horizontal fibers could be responsible for gating of other synaptic pathways, allowing an expression of some and suppression of others.

\section{References}

Allman JM, Meizin F, McGuinnes E (1985) Direction and velocity specific surround in three cortical visual areas of the owl monkey. Perception 14:105-126.

Artola A, Singer W (1990) The involvement of $N$-methyl-D-aspartate receptors in induction and maintenance of long-term potentiation in rat visual cortex. Eur J Neurosci 2:254-269.

Avoli M (1986) Inhibitory potentials in neurons of the deep layers of the in vitro neocortical slices. Brain Res 370:165-170.

Beaulieu C, Somogyi P (1990) Targets and quantitative distribution of GABAergic synapses in the visual cortex of the cat. Eur $J$ Neurosci 2:296-303.

Bishop PO, Coombs JS, Henry GH (1973) Receptive fields of simple cells in the cat striate cortex. J Physiol (Lond) 213:31-60.

Callaway EM, Katz LC (1990) Emergence and refinement of clustered horizontal connections in cat striate cortex. J Neurosci 10:1134-1153.

Chervin RD, Pierce PA, Connors BW (1988) Periodicity and directionality in the propagation of epileptiform discharges across neocortex. J Neurophysiol 60:1695-1713.

Connors BW, Prince DA (1982) Effects of the local anesthetic QX314 on the membrane properties of hippocampal pyramidal neurons. J Pharmacol Exp Ther 220:476-481.

Connors BW, Malenka RC, Silva LR (1988) Inhibition of neocortical pyramidal neurons in rat and cat: two types of postsynaptic potentials, and $\mathrm{GABA}_{\mathrm{A}}$ and $\mathrm{GABA}_{\mathrm{B}}$ receptor mediated responses. J Physiol (Lond) 406:443-468.

Creutzfeldt OD, Garey LJ, Kuroda R, Wolff JR (1977) The distrihution of degenerating axons after small lesions in the intact and isolated visual cortex of the cat. Exp Brain Res 27:419-440.

Dutar P, Nicoll RA (1988a) A physiological role for $\mathrm{GABA}_{\mathrm{B}}$ receptors in the central nervous system. Nature 332:156-158.

Dutar P, Nicoll RA (1988b) Pre- and postsynaptic GABA B $_{\mathrm{B}}$ receptors in the hippocampus have different pharmacological properties. Neuron 1:585-591.

Fairén A, Valverde FA (1980) A specialized type of neuron in the visual cortex of cat: a Golgi and electron microscope study of chandelier cells. J Comp Neurol 194:761-779.

Fairén A, DeFelipe J, Regidor J (1983) Nonpyramidal neurons: general account. In: Cerebral cortex, Vol 1, Cellular components of the cerebral cortex (Peters A, Jones EG, eds), pp 201-253. New York: Plenum.

Ferster D (1986) Orientation selectivity of synaptic potentials in neurons of cat primary visual cortex. J Neurosci 6:1284-1301.

Ferster D (1989) The synaptic inputs to simple cells of the cat visual cortex. In: Neural mechanisms of perception (Lam DM-K, Gilbert CD, eds), pp 63-85. Houston: Gulf.

Gabbott PLA, Martin KAC, Whitteridge D (1987) Connections between pyramidal neurons in layer 5 of cat visual cortex (area 17). J Comp Neurol 259:364-381.

Giffin K, Doyle JP, Nerbonne JM (1988) Comparison of excitable membrane properties in identified neurons from mammalian visual cortex. Soc Neurosci Abstr 14:297.

Gilbert CD, Wiesel TN (1979) Morphology and intracortical projections of functionally identified neurons in cat visual cortex. Nature 280:120-125.

Gilbert CD, Wiesel TN (1983) Clustered intrinsic connections in cat visual cortex. J Neurosci 3:1116-1133.

Gilbert CD, Wiesel TN (1985) Intrinsic connectivity and receptive field properties in visual cortex. Vision Res 25:365-374.

Gilbert CD, Wiesel TN (1989) Columnar specificity of intrinsic horizontal and corticocortical connections in cat visual cortex. J Neurosci 9:2432-2442.

Gilbert CD, Wiesel TN (1990) The influence of contextual stimuli on the orientation selectivity of cells in primary visual cortex of the cat. Vis Kes 30:1689-1701.

Hestrin S, Nicoll RA, Perkel DJ, Sah P (1990) Analysis of synaptic action in pyramidal cells using whole-cell recording from rat hippocampal slices. J Physiol (Lond) 422:203-225.

Horikawa K, Armstrong WE (1988) A versatile means of intracellular 
labeling: injection of biocytin and its detection with avidin conjugates. J Neurosci Methods 25:1-11.

Howe JR, Sutor B, Zieglgänsberger W (1987a) Baclofen reduces postsynaptic potentials of rat cortical neurones by an action other than its hyperpolarizing action. J Physiol (Lond) 384:539-569.

Howe JR, Sutor B, Zieglgänsberger W (1987b) Characteristics of longduration inhibitory postsynaptic potentials in rat neocortical neurons in vitro. Cell Mol Biol 7:1-18.

Hubel DH, Wiesel TN (1963) Shape and arrangement of columns in cat's striate cortex. J Physiol (Lond) 165:559-568.

Hubel DH, Wiesel TN (1967) Cortical and callosal connections concerned with the vertical meridian of the visual fields in the cat. J Neurophysiol 30:1561-1573.

Humphrey AL, Sur M, Uhlrich DJ, Sherman SM (1985) Projection patterns of individual $\mathrm{X}$ - and $\mathrm{Y}$-cell axons from the lateral geniculate nucleus to cortical area 17 in the cat. J Comp Neurol 233:159-189.

Innocenti GM (1980) The primary visual pathway through the corpus callosum: morphological and functional aspects in the cat. Arch Ital Biol 118:124-188.

Jones KA, Baughman RW (1988) NMDA- and non-NMDA receptor components of excitatory synaptic potentials recorded from cells in layer $\mathrm{V}$ of rat visual cortex. J Neurosci 8:3522-3534.

Katz LC (1987) Local circuitry of identified projection neurons in cat visual cortex brain slices. J Neurosci 7:1223-1249.

Kauer JA, Malenka RC, Nicoll RA (1988) A persistent postsynaptic modification mediates long-term potentiation in the hippocampus. Neuron 1:911-917.

Kerr DIB, Ong J, Johnston GAR, Abbenante J, Prager RH (1988) 2-Hydroxy-saclofen: an improved antagonist and at central and peripheral GABA ${ }_{B}$ receptors. Neurosci Lett 92:92-96.

Kisvárday ZF, Martin KAC, Freund TF, Magloczky Z, Whitteridge D, Somogyi P (1986) Synaptic targets of HRP-filled layer III pyramidal cells in the cat striate cortex. Exp Brain Res 64:541--552.

LeVay S (1973) Synaptic patterns in the visual cortex of the cat and monkey. Electron microscopy of Golgi preparations. J Comp Neurol 150:53-86.

LeVay S, Gilbert CD (1976) Laminar patterns of geniculocortical projection in the cat. Brain Res 113:1-19.

Lorente de Nó R (1944) Cerebral cortex: architecture, intracortical connections, motor projections. In: Physiology of the nervous system (Fulton JF, ed), pp 291-325. Oxford: Oxford UP.

Löwel S, Freeman B, Singer W (1987) Topographic organization of the orientation column system in large flat-mounts of the cat visual cortcx: a 2-dcoxyglucose study. J Comp Neurol 255:401-415.

Löwel S, Bischof H-J, Leutnecker B, Singer W (1988) Topographic relations between ocular dominance and orientation columns in the cat striate cortex. Exp Brain Res 71:33-46.

Martin KAC, Whitteridge D (1984) Form, function and intracortical projections of spiny neurones in the striate visual cortex of the cat. $J$ Physiol (Lond) 353:463-504.

Martin KAC, Somogyi P, Whitteridge D (1983) Physiological and morphological properties of identified basket cells in the cat's visual cortex. Exp Brain Res 50:193-200.

Mayer ML, Westbrook GL (1984) Mixed-agonist action of excitatory amino acids on mouse spinal cord neurones under voltage-clamp. $J$ Physiol (Lond) 354:29-53.

McCormick DA, Connors BW, Lighthall JW, Prince DA (1985) Comparative electrophysiology of pyramidal and sparscly spiny stcllatc neurons of the neocortex. J Neurophysiol 54:782-806.

McGuire B, Gilbert CD, Wiesel TN, Rivlin PK (1991) Target morphology and specificity of horizontal connections of pyramidal neurons in the primate visual cortex. J Comp Neurol, in press.

Morrison JH, Foote SL, Molliver ME, Bloom FE, Lidov HGW (1982) Noradrenergic and serotonergic fibers innervate complementary layers in monkey primary visual cortex: an immunohistological study. Proc Natl Acad Sci USA 79:2401-2405.

Naegele JR, Katz LC (1990) Cell surface molecules containing $N$-acetylgalactosamine are associated with basket cells and neurogliaform cells in cat visual cortex. J Neurosci 10:540-557.

Nelson JI, Frost BJ (1978) Orientation-selective inhibition from beyond the classic visual receptive field. Brain Res 139:359-365.

Nelson JI, Frost BJ (1985) Intracortical facilation among co-orientcd co-axially aligned simple cells in cat striate cortex. Exp Brain Res 61: 54-61.

Newberry NR, Nicoll RA (1985) Comparison of the action of baclofen with gamma-aminobutyric acid on rat hippocampal pyramidal cells in vitro. J Physiol (Lond) 360:161-185.

Orban GAB, Gulyas B, Vogels R (1987) Influence of a moving textured background on direction selectivity of cat striate neurons. J Neurophysiol 57:1792-1812.

Prince DA, Huguenard JR (1988) Functional properties of neocortical neurons. In: Neurobiology of neocortex (Rackic P, Singer W, eds), pp 153-176. New York: Wiley.

Rockland KS, Lund JS (1983) Intrinsic laminar lattice connections in primate visual cortex. J Comp Neurol 216:303-318.

Rockland KS, Virga A (1989) Terminal arbors of individual "feedback" axons projecting from area $\mathrm{V} 2$ to $\mathrm{V} 1$ in the Macaque monkey: a study using immunohistochemistry of anterogradely transported Phaseolus vulgaris-leucoagglutinin. J Comp Neurol 285:54-72.

Schwartzkroin PA, Mathers LH (1978) Physiological and morphological identification of a nonpyramidal hippocampal cell type. Brain Res 157:1-10.

Shatz CJ (1977) Anatomy of interhemispheric connections in the visual system of Boston Siamese and ordinary cats. J Comp Neurol 173:497-518.

Shirokawa T, Nishigori A, Kimura F, Tsumoto T (1989) Actions of excitatory amino acid antagonists on synaptic potentials of layer II/ III neurons of the cat's visual cortex. Exp Brain Res 78:489-500.

Sillito AM (1884) Functional considerations of the operations of GABAergic inhibitory processes in the visual cortex. In: Cerebral cortex Vol 2, Functional properties of cortical cells (Jones EG, Peters A, eds), pp 91-117. New York: Plenum.

Somogyi P, Freund TF, Cowey A (1982) The axo-axonic interneuron in the cerebral cortex of the rat, cat and monkey. Neuroscience 7 : $2577-2607$.

Somogyi P, Kisvárday ZF, Martin KAC, Whitteridge D (1983) Synaptic connections of morphologically identified and physiologically characterized large basket cells in the striate cortex of cat. Neuroscience 10:261-294.

Staftstrom CE, Schwindt PC, Chubb MC, Crill WE (1985) Properties of persistent sodium conductance and calcium conductance of layer $\mathrm{V}$ neurons from cat sensorimotor cortex in vitro. J Neurophysiol 53: $1153-1170$.

Sutor B, Hablitz JJ (1989a) EPSPs in rat neocortical neurons in vitro. I. Electrophysiological evidence for two distinct EPSPs. J Neurophysiol 61:621-634.

Sutor B, Hablitz JJ (1989b) EPSPs in rat neocortical neuron in vitro. II. Involvement of $N$-methyl-D-aspartate receptors in the generation of EPSPs. J Neurophysiol 61:607-620.

Thomson AM, Grirdlestone D, West DC (1988) Voltage-dependent currents prolong single-axon postsynaptic currents in layer III pyramidal neurons in rat neocortical slices. J Neurophysiol 60:1896-1906.

Tigges J, Tigges M, Anschel S, Cross NA, Letbetter WD, McBride RL (1981) Areal and laminar distribution of neurons interconnecting the central visual cortical areas $17,18,19$, and $\mathrm{MT}$ in the squirrel monkey (Saimiri). J Comp Neurol 202:539-560.

Toyama K (1988) Functional connections of the visual cortex. In: Neurobiology of neocortex (Rackic P, Singer W, eds), pp 203-217. New York: Wiley.

Toyama K, Kimura M, Tanaka K (1981a) Cross-correlation analysis of interneuronal connectivity on cat visual cortex. J Neurophysiol 46: 191-201.

Toyama K, Kimura M, Tanaka K (1981b) Organization of cat visual cortex as investigated by cross-correlation technique. J Neurophysiol 46:202-212.

Ts'o D, Gilbert CD, Weisel TN (1986) Relationships between horizontal connections and functional architecture in cat striate cortex as revealed by cross-correlation analysis. J Neurosci 6:1160-1170.

Watkins JC, Evans RH (1981) Excitatory amino acid transmitters. Annu Rev Pharmacol Toxicol 21:165-204.

Wiesel TN, Gilbert CD (1989) The Helmerich lecture: neural mechanisms of visual perception. In: Neural mechanisms of perception (Lam DM-K, Gilbert CD, eds), pp 7-33. Houston: Gulf. 